Open Access

\title{
Long-range transport of mutagens and other air pollutants from mainland East Asia to western Japan
}

Souleymane Coulibaly ${ }^{1}$, Hiroki Minami ${ }^{1}$, Maho Abe ${ }^{1}$, Tomohiro Hasei ${ }^{1}$, Tadashi Oro ${ }^{2}$, Kunihiro Funasaka ${ }^{3}$, Daichi Asakawa ${ }^{3}$, Masanari Watanabe ${ }^{4}$, Naoko Honda ${ }^{1,5}$, Keiji Wakabayashi $^{1,6}$ and Tetsushi Watanabe ${ }^{1 *}$

\begin{abstract}
Introduction: Asian dust events, transport of dust particles from arid and semi-arid areas in China and Mongolia to the east by prevailing westerlies, are often observed in Japan in spring. In recent decades, consumption of fossil fuels has markedly increased in mainland East Asia with rapid economic growth, and severe air pollution has occurred. A part of air pollutants including mutagens, such as polycyclic aromatic hydrocarbons (PAHs), generated in mainland East Asia are thought to be transported to Japan by the prevailing westerlies, like Asian dust, and winter monsoon. The objective of this study was to clarify the long-range transport of mutagens and other air pollutants in East Asia. Thus, we collected total suspended particles (TSP) at a rural town in western Japan, namely, Yurihama in Tottori Prefecture, for 1 year (June 2012-May 2013), and investigated their chemical constituents and mutagenicity.
\end{abstract}

Results: Many TSP collected from January to March showed high mutagenicity toward Salmonella typhimurium YG1024 with and without $\mathrm{S} 9 \mathrm{mix}$, and high levels of lead $(\mathrm{Pb})$ and sulfate ions $\left(\mathrm{SO}_{4}^{2-}\right)$, which are indicators of transboundary air pollutions from mainland East Asia, were detected in those TSP. A large amount of iron, which is an indicator of sand, was found in highly mutagenic TSP collected in March, but not in TSP collected in January and February. High levels of PAHs were detected in highly mutagenic TSP collected from January to March. The ratios of the concentration of fluoranthene to those of fluoranthene and pyrene suggested that the main source of PAHs in TSP collected in winter and spring was coal and biomass combustion. Backward trajectories of air masses on days when high levels of mutagenicity were found indicated that these air masses had traveled from eastern or northern China to Yurihama.

Conclusions: These results suggest that high levels of mutagens were transported from mainland East Asia to western Japan, and this transportation accompanied Asian dust in March, but not in January and February.

Keywords: Transboundary air pollution, Total suspended particles, Asian dust, Ames test, Polycyclic aromatic hydrocarbon

\footnotetext{
* Correspondence: watanabe@mb.kyoto-phu.ac.jp

${ }^{1}$ Department of Public Health, Kyoto Pharmaceutical University, 1

Misasagi-Shichonocho, Yamashinaku, Kyoto 607-8412, Japan

Full list of author information is available at the end of the article
}

(c) 2015 Coulibaly et al. Open Access This article is distributed under the terms of the Creative Commons Attribution 4.0 International License (http://creativecommons.org/licenses/by/4.0/), which permits unrestricted use, distribution, and reproduction in any medium, provided you give appropriate credit to the original author(s) and the source, provide a link to the Creative Commons license, and indicate if changes were made. The Creative Commons Public Domain Dedication waiver (http://creativecommons.org/publicdomain/zero/1.0/) applies to the data made available in this article, unless otherwise stated. 


\section{Introduction}

An Asian dust event is a meteorological phenomenon in which dust particles originating in arid and semi-arid areas in western China and Mongolia, such as the Gobi Desert and the Loess Plateau, are transported to the east by prevailing westerlies [1]. The Japan Meteorological Agency (JMA) has assessed Asian dust events in terms of visibility at 60 meteorological observatories across Japan, and has reported that Asian dust events were mainly observed there in spring (March-May) [2]. Moreover, the Light Detection and Ranging (LIDAR) system has been used to measure Asian dust at 12 sites in Japan [3]. The dust extinction coefficient based on LIDAR measurement can be used to estimate the amount of nonspherical dust particles, such as Asian dust. Ueda et al. [4] determined moderate Asian dust days $(0.066 / \mathrm{km}<$ dust extinction coefficient $\leq 0.105 / \mathrm{km})$ and heavy Asian dust days $(0.105 / \mathrm{km}<$ dust extinction coefficient) using LIDAR.

In addition to the prevailing westerlies in spring, a winter monsoon blows from mainland East Asia to Japan in winter (December-February). In China, atmospheric concentrations of fine particulate matter $\left(\mathrm{PM}_{2.5}\right.$, airborne particles with an aerodynamic diameter of less than or equal to $2.5 \mu \mathrm{m}$ ) were reported to be high in winter [5]. Winter heating was identified as a major contributor to the severe pollution, and coal combustion was revealed to be a main source [5]. In 2013, the International Agency for Research on Cancer (IARC) reported that outdoor pollution and particulate matter are carcinogenic to humans (Group 1) [6]. Mutagenic/carcinogenic substances, such as polycyclic aromatic hydrocarbons (PAHs), are formed by the incomplete combustion of organic matter such as fossil fuels [7] and these substances were mainly detected in fine particles $[8,9]$. Therefore, long-range transport of anthropogenic air pollutants including mutagens may occur in East Asia by the winter monsoon and the prevailing westerlies in winter and spring, respectively. However, there are few reports on transboundary air pollution with mutagens in East Asia.

The objective of this study was to clarify the longrange transport of mutagens in East Asia; for this, we measured air pollutants at Yurihama in Tottori Prefecture, Japan, from June 2012 to May 2013. Yurihama is a rural town located on the west coast of Japan, where there are no major air pollution sources. In this study, air pollution was frequently examined in winter and spring by quantifying total suspended particles (TSP), iron (Fe), lead $(\mathrm{Pb})$, sulfate ions $\left(\mathrm{SO}_{4}^{2-}\right)$, nitrate ions $\left(\mathrm{NO}_{3}^{-}\right)$, polycyclic aromatic hydrocarbons (PAHs), and bacterial mutagenicity. Fe is a main constituent of the earth's crust and is an indicator of the amount of sand in the atmosphere [10]. $\mathrm{Pb}$ is a minor constituent of the crust and is emitted into the atmosphere by the combustion of coal, and refuse incineration [11]. Anthropogenic emission of sulfur oxides and nitrogen oxides is caused by the combustion of fossil fuels, such as coal and petroleum. The increases of atmospheric $\mathrm{Pb}$ and $\mathrm{SO}_{4}^{2-}$ in Japan suggest air pollution by the long-range transport from mainland East Asia [12]. PAHs are produced by the imperfect combustion of organic matter, such as fossil fuels and biomass [7]. In this study, ten PAHs classified as priority pollutants by the United States Environmental Protection Agency were analyzed to estimate the amounts of PAHs in TSP. The transport routes of air masses were estimated by backward trajectory analysis. We compared our results with the occurrences of Asian dust events found by observations conducted by JMA and the National Institute for Environmental Studies (NIES) using visibility and LIDAR, respectively.

\section{Materials and methods Reagents}

Benzo[b]fluoranthene (BbF, CAS 205-99-2), benzo[k]fluoranthene (BkF, CAS 207-08-9), benzo[a]pyrene (BaP, CAS 50-32-8), indeno[1,2,3-cd] pyrene (IcdP, CAS 19339-5), nitric acid $\left(\mathrm{HNO}_{3}\right.$, CAS 7697-37-2), hydrochloric acid (HCl, CAS 7647-01-0), hydrofluoric acid (HF, CAS 7664-39-3), and perchloric acid $\left(\mathrm{HClO}_{4}, \mathrm{CAS} 7601-90-3\right)$ were purchased from Wako Pure Chemical Industries, Ltd. (Osaka, Japan). Fluoranthene (FR, CAS 206-44-0) and pyrene (PY, CAS 129-00-0) were obtained from Nacalai Tesque Inc. (Kyoto, Japan). Benz $[a]$ anthracene (BaA, CAS 56-55-3), dibenz $[a, h]$ anthracene (DahA, CAS 53-70-3), 1nitropyrene (CAS 5522-43-0), and 2-acetylaminofluorene (CAS 53-96-3) were purchased from Tokyo Chemical Industry Co., Ltd. (Tokyo, Japan). Chrysene (CHR, CAS 218-01-9), benzo[ghi]perylene (BghiP, CAS 191-24-2), phenobarbital (CAS 50-06-6), and $\beta$-naphthoflavone (CAS 6051-87-2) were purchased from Sigma-Aldrich Co. LLC (St. Louis, MO, USA). Quartz filters were obtained from Pall Life Sciences (Port Washington, NY, USA).

\section{Sampling methodology and sample preparation}

TSP were collected on the rooftop of Tottori Prefectural Institute of Health and Environmental Sciences at Yurihama Town $\left(133.88^{\circ} \mathrm{E}, 35.49^{\circ} \mathrm{N}\right)$ in Tottori Prefecture. Tottori Prefecture is located in western Japan on the coast of the Japan Sea (Fig. 1). Yurihama is a small town, with a population of about 17,000 in 2013. The sampling site is located at a distance of $1.4 \mathrm{~km}$ from the coast and there were no major air pollution sources in the surrounding area. The particulates were collected on quartz filters at a flow rate of $1000 \mathrm{~L} / \mathrm{min}$ with a high-volume air sampler (HV1000R, Shibata Scientific Technology, Soka, Japan) [8]. Sampling began at about 9 AM (Japan Standard Time, JST) and was completed at about 9 AM the next day. Sampling was performed for 4 days per month from June to November 2012, and from 13 to 19 days per month from December 2012 to May 2013. 


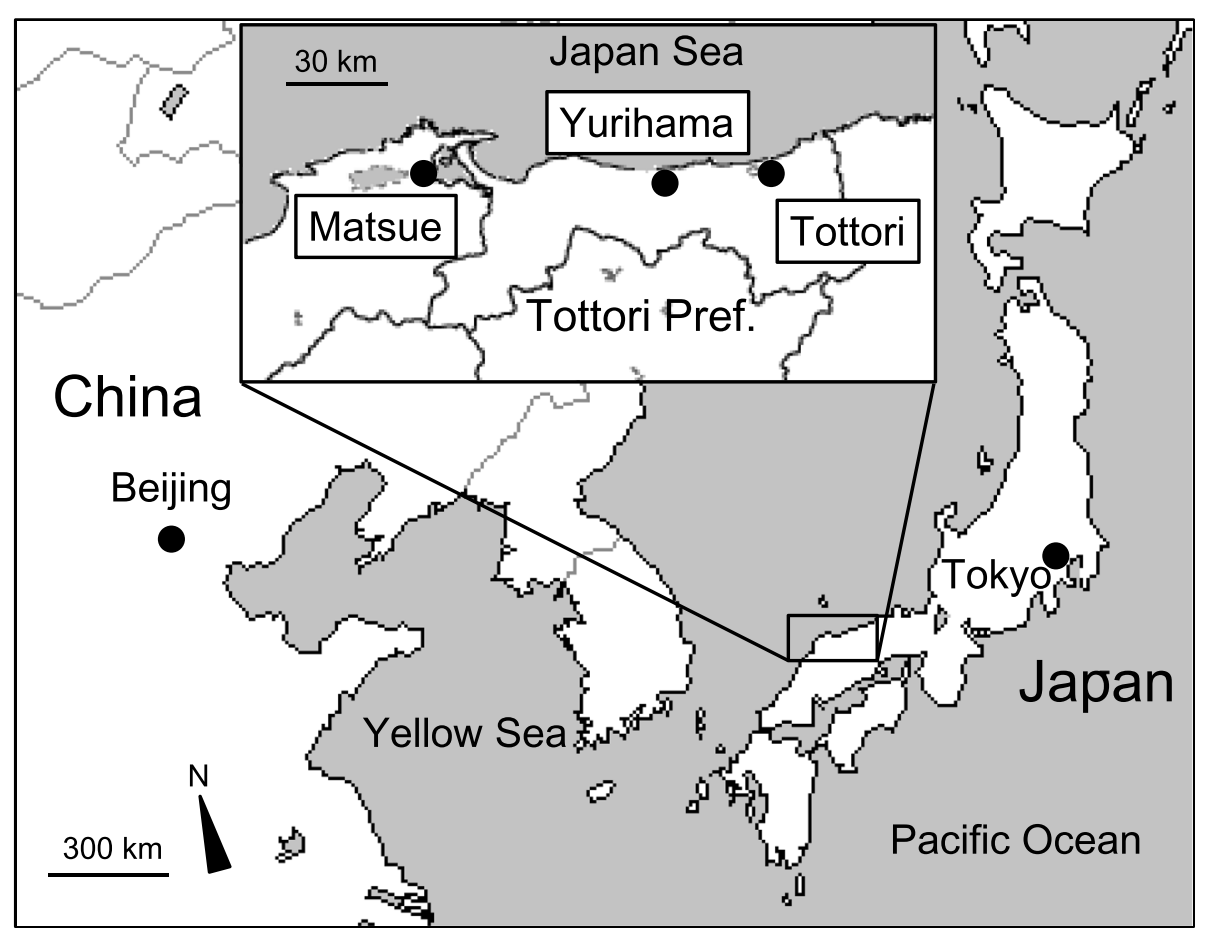

Fig. 1 Map of the sampling site and the observation sites of Asian dust event. Yurihama is a sampling site of TSP. Tottori is an observatory site of Asian dust event by JMA [2]. Observation of Asian dust event using LIDAR was performed at Matsue by NIES [3]

The total number of sampling days was 118 from June 2012 to May 2013. This sampling period was divided into four seasons, namely, summer (June-August), autumn (September-November), winter (December-February), and spring (March-May).

The filters were weighed before and after sampling after being stored at $50 \%$ relative humidity and $20{ }^{\circ} \mathrm{C}$. To calculate the atmospheric concentration of TSP, the weight of TSP collected on a filter was divided by the volume of the air that had passed through the filter.

\section{Analysis of metals}

Ten percent of each sample filter was cut into small pieces and digested with a mixture of $\mathrm{HNO}_{3} / \mathrm{HCl}$ and then with a mixture of $\mathrm{HNO}_{3} / \mathrm{HF} / \mathrm{HClO}_{4}$ [13]. The solution was heated to almost dryness and then cooled to room temperature. After filtration with the addition of distilled water, the sample solution was re-heated and finally adjusted with $0.2 \mathrm{M} \mathrm{HNO}_{3}$. Fe and $\mathrm{Pb}$ were respectively analyzed by inductively coupled plasmaatomic emission spectrometry (IRIS 1000, Thermo Fisher Scientific, Waltham, MA, USA) and Zeeman electro-thermal atomic absorption spectrometry (Analyst 600, PerkinElmer, Waltham, MA, USA) [14]. When the reference urban atmospheric particles (NIST, SRM1648a) were analyzed by this method, the recovery rates of Fe and $\mathrm{Pb}$ were 96 and $83 \%$ (each, $n=3$ ), respectively. The limit of quantification (LOQ) of $\mathrm{Fe}$ and $\mathrm{Pb}$ were as follows: $\mathrm{Fe}$, $99 \mathrm{ng} / \mathrm{m}^{3}$; and $\mathrm{Pb}, 5.1 \mathrm{ng} / \mathrm{m}^{3}$.

\section{Analysis of water-soluble ionic species}

Five percent of each sample filter was cut into small pieces and extracted with distilled water by ultra-sonication. A portion of the extract was filtrated using a syringe filter (DISMIC-25CS, Advantec Co., Ltd., Tokyo, Japan). SO ${ }_{4}^{2-}$ and $\mathrm{NO}_{3}^{-}$were measured using an ion chromatograph (600E/700, Waters Co., Ltd., Milford, MA, USA) with an anion suppressor (ASRS 300, Thermo Fisher Scientific, Waltham, MA, USA) and an anion-exchange column (AS4A-SC, Thermo Fisher Scientific, Waltham, MA, USA) [15]. The $\mathrm{LOQ}$ of $\mathrm{SO}_{4}^{2-}$ and $\mathrm{NO}_{3}^{-}$were as follows: $\mathrm{SO}_{4}^{2-}$, $46 \mathrm{ng} / \mathrm{m}^{3}$; and $\mathrm{NO}_{3}^{-}, 131 \mathrm{ng} / \mathrm{m}^{3}$.

\section{Analysis of PAHs}

Forty percent of each sample filter was cut into small pieces and extracted with methanol by ultra-sonication [8]. After filtration, the extract was evaporated to dryness. Ten PAHs, namely, FR, PY, BaA, CHR, BbF, BkF, $\mathrm{BaP}$, DahA, BghiP, and IcdP, were analyzed by highperformance liquid chromatography using a fluorescence detector (RF-20AXs, Shimadzu Co., Kyoto, Japan). PAHs were separated with a Wakosil-PAHs column $(4.6 \mathrm{~mm} \times$ $250 \mathrm{~mm}$, Wako Pure Chemical Industries, Ltd., Osaka, Japan) and measured with the following excitation (Ex)/ emission (Em) wavelengths: FR and PY, $250 \mathrm{~nm} / 420 \mathrm{~nm}$; 
$\mathrm{BaA}, \mathrm{CHR}, \mathrm{BbF}$, and BkF, $270 \mathrm{~nm} / 400 \mathrm{~nm}$; BaP, DahA, and BghiP, $296 \mathrm{~nm} / 410 \mathrm{~nm}$; and IcdP, $300 \mathrm{~nm} / 500 \mathrm{~nm}$ [8]. The LOQ of PAHs were as follows: FR, $101 \mathrm{fg} / \mathrm{m}^{3}$; PY, $165 \mathrm{fg} / \mathrm{m}^{3}$; BaA, $14 \mathrm{fg} / \mathrm{m}^{3}$; CHR, $98 \mathrm{fg} / \mathrm{m}^{3} ; \mathrm{BbF}$, $127 \mathrm{fg} / \mathrm{m}^{3}$; BkF, $63 \mathrm{fg} / \mathrm{mm}^{3}$; BaP, $14 \mathrm{fg} / \mathrm{m}^{3}$; DahA, $39 \mathrm{fg} /$ $\mathrm{m}^{3}$; BghiP, $50 \mathrm{fg} / \mathrm{m}^{3}$; and IcdP $112 \mathrm{fg} / \mathrm{m}^{3}$.

\section{Mutagenicity assay}

Forty percent of each sample filter was cut into small pieces and extracted with methanol by ultra-sonication [8]. After filtration, the extract was evaporated to dryness. The residues dissolved in dimethyl sulfoxide were assayed using Salmonella typhimurium YG1024 in the absence and presence of a mammalian metabolic system, S9 mix [16]. YG1024 was kindly provided by Dr. Nohmi from the National Institute of Health; it is an O-acetyltransferase-overproducing derivative of $S$. typhimurium TA98 [17], and is sensitive to the mutagenicity of airborne particles $[8,18]$. The S9 mix was prepared with S9 from livers of male Sprague-Dawley rats (SLC Inc., Shizuoka, Japan) treated with phenobarbital and $\beta$ naphthoflavone [19]. Positive controls without and with S9 mix were 1-nitropyrene and 2-acetylaminofluorene, respectively. The slope of the dose-response curve obtained with three doses and duplicate plates at each dose was adopted as the mutagenic potency. Samples were judged as positive when they induced twofold increases over the average of spontaneous revertants and showed well-behaved concentration-response patterns.

\section{Statistical analysis}

Statistical analysis (Dunnett's test, calculation of correlation coefficients, and others) was performed with Microsoft Office Excel 2013. The differences of the diagnostic ratios of PAHs in TSP collected in summer from that in other seasons were analyzed by non-repeated one-way ANOVA followed by Dunnett's test.

\section{Backward trajectory analysis}

Backward trajectories were estimated with the HYSPLIT model provided by the National Oceanic and Atmospheric Administration (NOAA) of the United States of America [20]. The backward trajectories started at 10 PM (JST), and the height was set at $1500 \mathrm{~m}$. Backward trajectory analysis was performed using model vertical velocity, and the trajectory duration was $72 \mathrm{~h}$.

\section{Results}

\section{Concentrations of TSP and chemical constituents}

Table 1 shows the mean value and standard deviation of the concentration of TSP and the chemical constituents in each season. The highest mean values were obtained in spring for TSP and all chemical constituents, except for total PAHs. We analyzed 10 PAHs to estimate the levels of PAHs in TSP and calculated the sum of the concentrations of these 10 PAHs as total PAHs. The highest mean value for total PAHs was found in winter $\left(1.05 \mathrm{ng} / \mathrm{m}^{3}\right)$, and it was close to that of spring $(0.92 \mathrm{ng} /$ $\mathrm{m}^{3}$ ). Ten PAHs were detected in almost all TSP. The amounts of a few PAHs, such as DahA, were lower than LOQ in several samples.

Figure 2 shows the atmospheric concentrations of TSP and chemical constituents in the particles at Yurihama from June 2012 to May 2013. JMA registered Asian dust events on March 8, 9, 19, and 20, 2013, at Tottori, which is $34 \mathrm{~km}$ away from the sampling site (Fig. 1). LIDAR measurement was performed at Matsue, which is $73 \mathrm{~km}$ away from the sampling site (Fig. 1). On sampling days when dust extinction coefficients were higher than $0.066 / \mathrm{km}$, Asian dust events were considered to have been detected [4], and high dust extinction coefficients (>0.066/km) were found on March 7, 8, 9, and 19, April 30, and May 30, 2013. As shown in Fig. 2, the concentrations of TSP and Fe were remarkably high on March 8 and 9, and high levels of particles and Fe, namely, close to or

Table 1 Atmospheric concentrations and mutagenicity of TSP and their chemical constituents

\begin{tabular}{lllll}
\hline & Summer & Autumn & Winter & Spring \\
\hline $\mathrm{TSP}\left(\mu \mathrm{g} / \mathrm{m}^{3}\right)$ & $22.1 \pm 12.0$ & $29.3 \pm 8.0$ & $22.6 \pm 14.3$ & $48.4 \pm 37.4$ \\
$\mathrm{Fe}\left(\mathrm{ng} / \mathrm{m}^{3}\right)$ & $76.7 \pm 66.4$ & $145.7 \pm 130.8$ & $126.8 \pm 130.5$ & $709.4 \pm 844.0$ \\
$\mathrm{~Pb}\left(\mathrm{ng} / \mathrm{m}^{3}\right)$ & $8.2 \pm 13.9$ & $7.3 \pm 4.8$ & $9.7 \pm 8.5$ & $15.9 \pm 15.2$ \\
$\mathrm{SO}_{4}^{2-}\left(\mu \mathrm{g} / \mathrm{m}^{3}\right)$ & $5.03 \pm 5.50$ & $4.78 \pm 2.28$ & $4.36 \pm 3.47$ & $7.38 \pm 4.88$ \\
$\mathrm{NO}_{3}^{-}\left(\mu \mathrm{g} / \mathrm{m}^{3}\right)$ & $0.45 \pm 0.22$ & $1.05 \pm 0.91$ & $1.39 \pm 1.07$ & $2.49 \pm 2.70$ \\
Total PAHs $\left(\mathrm{ng} / \mathrm{m}^{3}\right)$ & $0.21 \pm 0.16$ & $0.57 \pm 0.38$ & $1.05 \pm 0.66$ & $0.92 \pm 0.73$ \\
Mutagenicity $\left(\mathrm{revertant} / \mathrm{m}^{3}\right)$ & & & & $12.7 \pm 12.9$ \\
\multicolumn{1}{c}{ Without S9 mix } & $3.5 \pm 1.6$ & $9.7 \pm 5.8$ & $19.6 \pm 13.7$ & $13.1 \pm 18.7$ \\
\multicolumn{1}{l}{ With S9 mix } & $1.8 \pm 1.3$ & $7.2 \pm 5.2$ & 13.4 & \\
\hline
\end{tabular}

The intervals for collecting TSP were as follows: summer (Jun.-Aug. 2012, $n=12$ ), autumn (Sep.-Nov. 2012, $n=12$ ), winter (Dec. 2012-Feb. 2013, $n=42$ ), and spring (Mar.-May 2013, $n=52$ )

Numbers indicate the mean \pm standard deviation

Total PAHs means the sum of the concentrations of 10 PAHs (FR, PY, CHR, BaA, BaP, BbF, BkF, DahA, IcdP, and BghiP) 


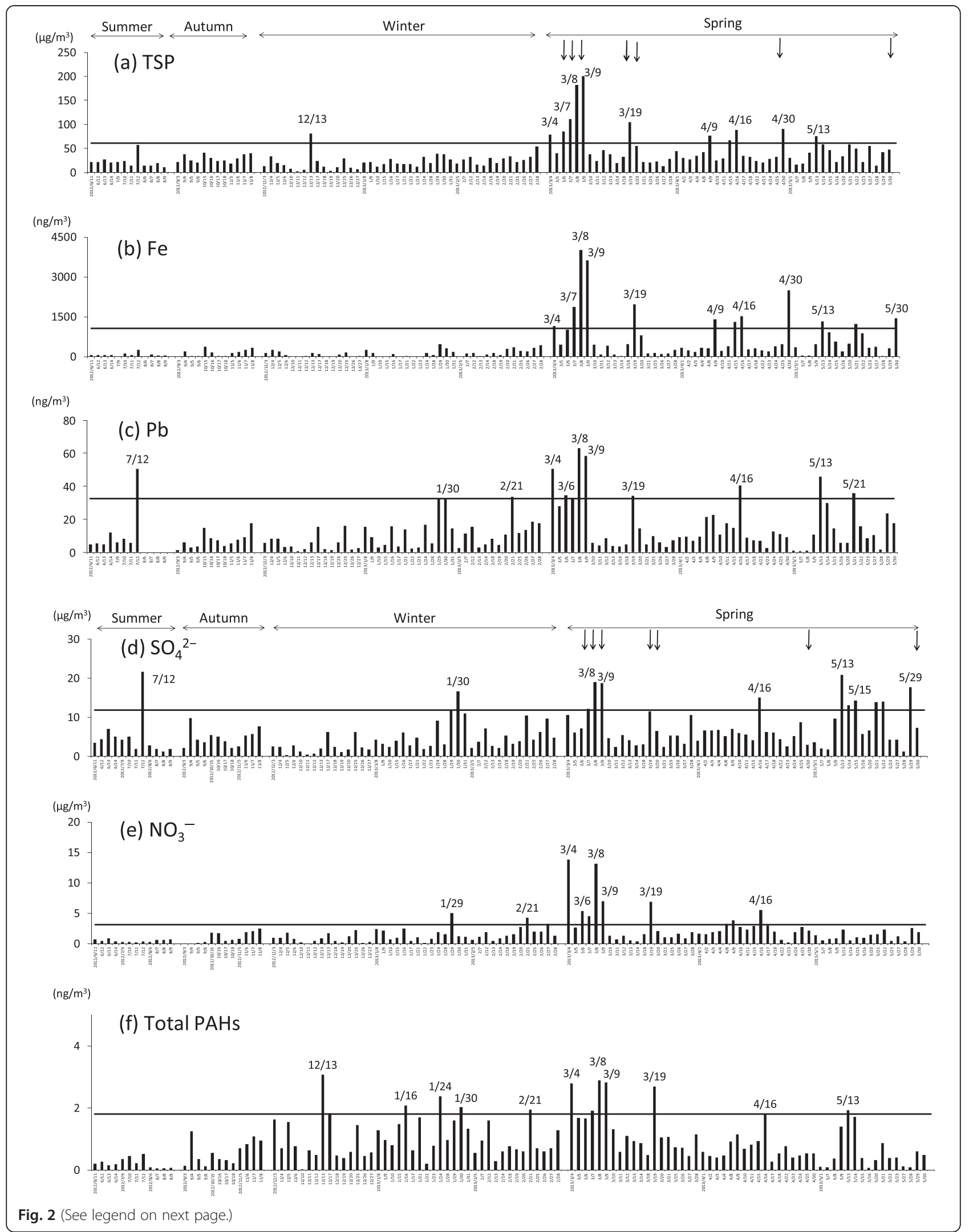


(See figure on previous page.)

Fig. 2 Concentrations of TSP and chemical constituents in TSP collected at Yurihma. Atmospheric concentrations of a TSP, b Fe, c Pb, d SO ${ }_{4}^{2-}$, e $\mathrm{NO}_{3}^{-}$, and $\mathbf{f}$ total PAHs were analyzed. The intervals for collecting TSP were as follows: summer (June-August), autumn (September-November), winter (December-February), and spring (March-May). Arrows show dates of Asian dust events registered by the JMA (March 8, 9, 19, and 20) or indicated by LIDAR (March 7, 8, 9, and 19, April 30, and May 30). Horizontal lines show the 90 th percentile of TSP $\left(61.0 \mu \mathrm{g} / \mathrm{m}^{3}\right)$, Fe $\left(1061 \mathrm{ng} / \mathrm{m}^{3}\right)$, $\mathrm{Pb}\left(32.4 \mathrm{ng} / \mathrm{m}^{3}\right), \mathrm{SO}_{4}^{2-}\left(11.8 \mu \mathrm{g} / \mathrm{m}^{3}\right), \mathrm{NO}_{3}^{-}\left(3.10 \mu \mathrm{g} / \mathrm{m}^{3}\right)$, and total PAHs $\left(1.81 \mathrm{ng} / \mathrm{m}^{3}\right)$. Total PAHs means the sum of the concentrations of $10 \mathrm{PAHs}$ (FR, PY, CHR, BaA, BaP, BbF, BkF, DahA, IcdP, and BghiP)

higher than the 90th percentiles, were found in March and April on common sampling days, such as March 4, 7, 8, 9, and 19, and April 9, 16, and 30. High levels of $\mathrm{Pb}$ and $\mathrm{SO}_{4}^{2-}$ were detected on common sampling days, such as July 12, January 30, March 8, 9, and 19, April 16, and May 13. The atmospheric concentrations of $\mathrm{NO}_{3}^{-}$were high on January 29, March 4, 8, 9, and 19, and April 16. As described above, atmospheric concentrations of particles, $\mathrm{Fe}, \mathrm{Pb}, \mathrm{SO}_{4}^{2-}$, and $\mathrm{NO}_{3}^{-}$were high on many common days, such as March 8 , 9, and 19 and April 16. High levels of total PAHs were mainly found from January to March, such as January 16, 24, and 30, February 21, and March 4, 8, 9, and 19. Although high levels of particles and chemical constituents were detected on days when Asian dust events were found by visibility and LIDAR, there were many other sampling days that showed high levels of TSP and chemical constituents.

\section{Mutagenicity of TSP}

The mean value and standard deviation of the mutagenicity of organic extracts of TSP collected at Yurihama in each season are shown in Table 1. The highest mean values were found both without and with $\mathrm{S} 9 \mathrm{mix}$ in winter (without $\mathrm{S} 9 \mathrm{mix}, 19.6$ revertants $/ \mathrm{m}^{3}$; with $\mathrm{S} 9 \mathrm{mix}, 17.5$ revertants $/ \mathrm{m}^{3}$ ), and the mean values of mutagenicity without and with $\mathrm{S} 9 \mathrm{mix}$ were the lowest in summer.

Figure 3 shows the mutagenicities of organic extracts of TSP collected at Yurihama from June 2012 to May 2013 in YG1024 without and with S9 mix. Most of the highly mutagenic samples were collected from January to March, such as January 16, 29, and 30, February 12 and 21, and March 4, 8, and 19. On those days, high mutagenicities were found both without and with S9 mix. Mutagenicities of the whole samples without and with S9 mix were strongly correlated, and the correlation coefficient was 0.840 . The highest mutagenicities without and with S9 mix were found on March 4 (70 revertants/ $\mathrm{m}^{3}$ without $\mathrm{S} 9 \mathrm{mix}, 96$ revertants $/ \mathrm{m}^{3}$ with $\left.\mathrm{S} 9 \mathrm{mix}\right)$.

\section{Correlations between mutagenicity and concentrations of TSP and their constituents}

As shown in Table 1 and Fig. 3, potent mutagenicity was found for samples collected in winter and spring. To analyze the association between the potent mutagenicity and other factors, we carried out statistical analyses for samples collected in winter and spring. Table 2 shows

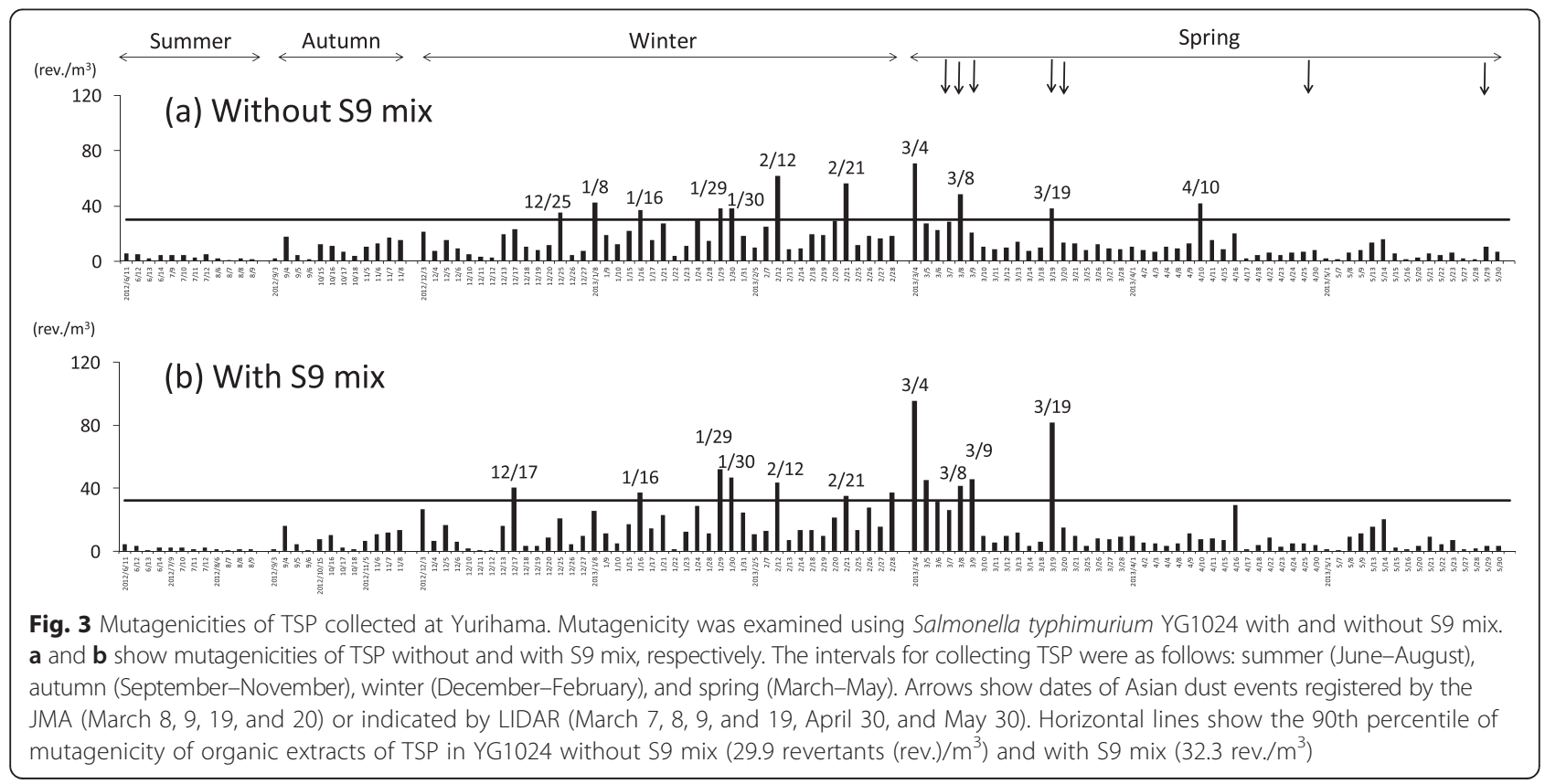


Table 2 Coefficients of correlation between mutagenicity and concentrations of TSP and their constituents

\begin{tabular}{llllll}
\hline & \multicolumn{2}{l}{ Without S9 mix } & & \multicolumn{2}{l}{ With S9 mix } \\
\cline { 2 - 3 } & Winter & Spring & & Winter & Spring \\
\hline $\mathrm{TSP}$ & 0.458 & 0.537 & & 0.547 & 0.600 \\
$\mathrm{Fe}$ & 0.554 & 0.490 & & 0.686 & 0.529 \\
$\mathrm{~Pb}$ & 0.777 & 0.680 & & 0.853 & 0.719 \\
$\mathrm{SO}_{4}^{2-}$ & 0.663 & 0.378 & & 0.777 & 0.407 \\
$\mathrm{NO}_{3}^{-}$ & 0.705 & 0.847 & & 0.670 & 0.810 \\
Total PAHs & 0.657 & 0.783 & & 0.697 & 0.853 \\
\hline
\end{tabular}

The intervals for collecting TSP were as follows: winter (Dec. 2012-Feb. 2013, $n=42$ ), spring (Mar.-May 2013, $n=52$ ). Total PAHs means the sum of the concentrations of 10 PAHs (FR, PY, CHR, BaA, BaP, BbF, BkF, DahA, lcdP, and BghiP)

the coefficients of correlations between the mutagenicity and the concentrations of TSP and the constituents in winter and spring. Strong positive correlations, namely, with correlation coefficients greater than 0.7 , were obtained for $\mathrm{Pb}, \mathrm{SO}_{4}^{2-}, \mathrm{NO}_{3}^{-}$, and total PAHs without and/or with S9 mix. Moderate positive correlations, namely, with correlation coefficients from 0.5 to 0.7 , were found for TSP and Fe without and/or with S9 mix.

As shown in Figs. 2 and 3, high levels of contaminants and mutagenicity were found for samples collected in March. Therefore, we carried out statistical analyses for samples collected in March. As shown in Table 3, the concentrations of TSP and Fe were very strongly correlated with that of $\mathrm{Pb}$ and $\mathrm{SO}_{4}^{2-}$, with correlation coefficients greater than 0.9. The concentration of $\mathrm{Pb}$ was strongly correlated with the concentrations of other combustion products, namely, $\mathrm{SO}_{4}^{2-}, \mathrm{NO}_{3}^{-}$, and PAHs. In addition, the mutagenicity of TSP showed strong positive association with the concentrations of $\mathrm{Pb}, \mathrm{NO}_{3}^{-}$, and total PAHs without and with S9 mix.

\section{Ratio of concentration of FR to that of FR and PY ([FR]/ $([F R]+[P Y]))$}

To estimate the source of PAHs, the ratio of the concentration of FR to that of FR and PY $([\mathrm{FR}] /([\mathrm{FR}]+[\mathrm{PY}]))$ was calculated. Figure 4 shows the $[\mathrm{FR}] /([\mathrm{FR}]+[\mathrm{PY}])$ ratio for TSP collected at Yurihama in each season. The mean values of $[\mathrm{FR}] /([\mathrm{FR}]+[\mathrm{PY}])$ ratio measured in winter and spring were 0.54 and 0.50 , respectively. The ratios measured in these seasons were significantly higher $(p<0.01)$ than that in summer. On the other hand, the mean value of $[F R] /([F R]+[P Y])$ ratio measured in autumn (0.48) was higher than that in summer (0.44), but the difference of the ratios between the two seasons was not significant.

\section{Backward trajectory analysis}

Figure 5 shows backward trajectories of the air masses on days when high levels of mutagenicity were found, namely, the mutagenic activities were close to or higher than the 90th percentile of the whole sample (Fig. 3). Trajectories from Yurihama on January 29 and March 4 and 8 indicate that air masses had traveled from eastern China. On the other hand, air masses that arrived on January 16 and 30, February 12 and 21, and March 19 were considered to have come from northern China, where the Gobi Desert is located. The backward trajectories of the air masses on February 28 and March 5, when high levels of mutagenicity were found (Fig. 3), were similar to those on January 30 and March 19, and air masses were speculated to have moved from northern China (data not shown). Similarly, the backward trajectories of air masses on March 7 and 9, when high values were found for most of the indicators of air pollution analyzed in this study, resembled that on March 8 (data not shown).

Table 3 Correlation coefficients among the concentrations of TSP and the constituents and the mutagenicity of TSP collected in March

\begin{tabular}{|c|c|c|c|c|c|c|c|c|}
\hline & \multicolumn{6}{|c|}{ Concentration } & \multicolumn{2}{|l|}{ Mutagenicity } \\
\hline & $\overline{\mathrm{TSP}}$ & $\mathrm{Fe}$ & $\mathrm{Pb}$ & $\mathrm{SO}_{4}^{2-}$ & $\mathrm{NO}_{3}^{-}$ & $\overline{\text { Total PAHs }}$ & Without S9 mix & With 59 mix \\
\hline \multicolumn{9}{|l|}{ Concentration } \\
\hline TSP & 1.000 & & & & & & & \\
\hline $\mathrm{Fe}$ & 0.984 & 1.000 & & & & & & \\
\hline $\mathrm{Pb}$ & 0.914 & 0.901 & 1.000 & & & & & \\
\hline $\mathrm{SO}_{4}^{2-}$ & 0.928 & 0.933 & 0.891 & 1.000 & & & & \\
\hline $\mathrm{NO}_{3}^{-}$ & 0.755 & 0.770 & 0.914 & 0.780 & 1.000 & & & \\
\hline Total PAHs & 0.864 & 0.849 & 0.941 & 0.866 & 0.890 & 1.000 & & \\
\hline \multicolumn{9}{|l|}{ Mutagenicity } \\
\hline Without $\$ 9$ mix & 0.567 & 0.577 & 0.804 & 0.602 & 0.936 & 0.830 & 1.000 & \\
\hline With $\$ 9$ mix & 0.572 & 0.555 & 0.780 & 0.589 & 0.833 & 0.864 & 0.904 & 1.000 \\
\hline
\end{tabular}

Total PAHs means the sum of the concentrations of 10 PAHs (FR, PY, CHR, BaA, BaP, BbF, BkF, DahA, IcdP, and BghiP) 


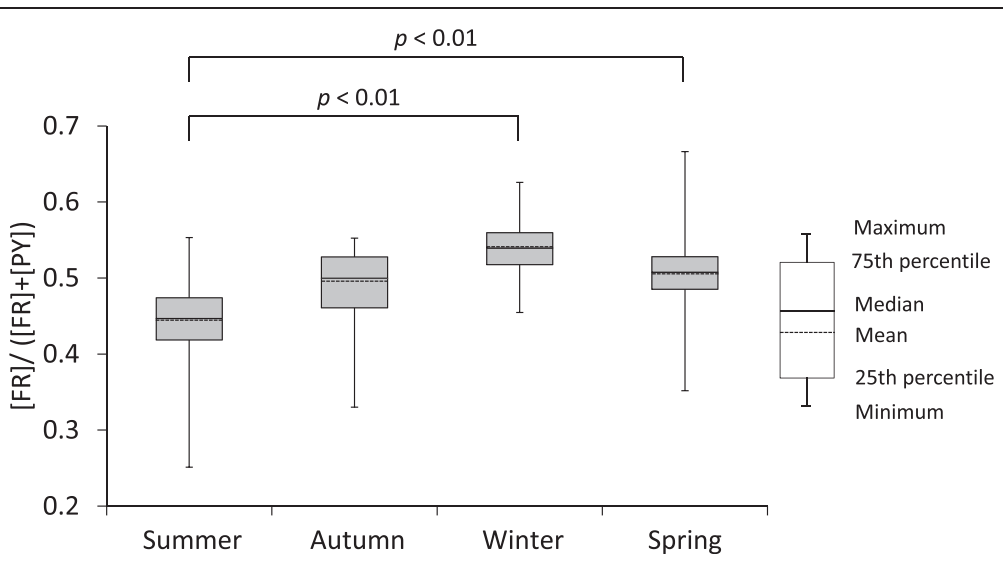

Fig. 4 Ratio of concentration of $[\mathrm{FR}] /([\mathrm{FR}]+[\mathrm{PY}]))$ measured at Yurihama. The intervals for collecting TSP were as follows: summer (June-August), autumn (September-November), winter (December-February), and spring (March-May). Statistical analysis was performed on the ratios of $[\mathrm{FR}] /([\mathrm{FR}]+[\mathrm{PY}])$ by Dunnett's test

\section{Discussion}

To clarify the effect of the long-range transport of air pollutants from mainland East Asia on the air in western Japan, we collected TSP at Yurihama for 1 year from June 2012 to May 2013, and quantified their chemical constituents and genotoxicity. Yurihama is located in western Japan on the coast of the Japan Sea, and there were no major air pollution sources in the surrounding area. In this study, we analyzed the inorganic and organic substances and mutagenicity. It is well-known that PAHs are generated by imperfect combustion of organic matter, such as fossil fuels [7], and many PAHs show mutagenicity toward S. typhimurium YG1024 with S9 mix [21]. High mutagenicity was found for many TSP collected at Yurihama from January to March without and with S9 mix, and the activity level was comparable

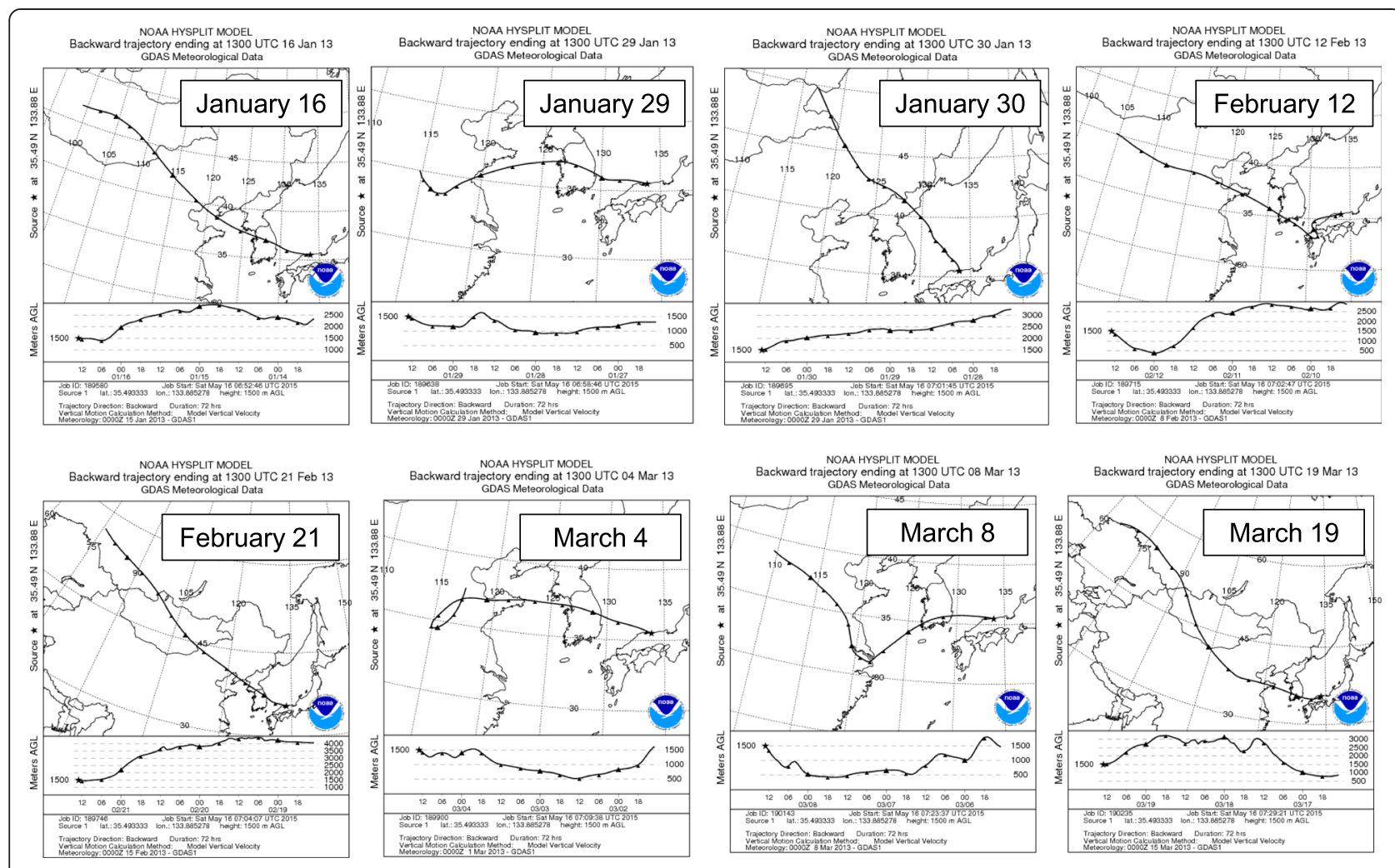

Fig. 5 Backward trajectories of air masses from Yurihama. Backward trajectories of air masses for $72 \mathrm{~h}$ were calculated using the HYSPLIT model provided by the NOAA of the USA [22] 
to those found in medium-sized cities in Japan, such as Sasebo city [8]. The mutagenic activity of TSP was moderately or strongly correlated with the atmospheric concentration of total PAHs and other combustion products, such as $\mathrm{NO}_{3}^{-}$, both without and with $\mathrm{S} 9$ mix (Table 2). Because PAHs are formed by the combustion of organic matter, dominant mutagens in the TSP may be combustion products, and a part of the mutagenicity of TSP with S9 mix may be attributable to PAHs.

In January 2013, a long-lasting episode of severe haze occurred in northern, central, southern, and eastern China [22, 23]. Wang et al. [22] reported that the two most severe episodes occurred during January 9-15 and 25-31 in the Beijing-Tianjin-Hebei area, and monthly averaged daily concentrations of fine particulate matter $\left(\mathrm{PM}_{2.5}\right)$ were very high. Mutagenicity and mutagens, such as PAHs, were mainly detected in fine particles [8]. In the present study, many of the highly mutagenic samples, which were close to or higher than the 90th percentile of the whole sample, were collected at Yurihama in January and February, such as January 29 and 30, and February 21, and high levels of total PAHs were found on those days (Fig. 2). The atmospheric concentrations of $\mathrm{Pb}$ and $\mathrm{SO}_{4}^{2-}$ were also high, but those of TSP and Fe were moderate (Fig. 2). As shown in Fig. 5, the backward trajectories suggest that air masses that arrived on those days had come from northern or eastern China. These results suggest that mutagenic substances were transported from mainland East Asia without a large amount of soil, namely, Asian dust, in January and February.

On the other hand, high levels of TSP and chemical constituents $\left(\mathrm{Fe}, \mathrm{Pb}, \mathrm{SO}_{4}^{2-}, \mathrm{NO}_{3}^{-}\right.$, and $\left.\mathrm{PAHs}\right)$ were found in March, such as on March 4, 7, 8, 9, and 19 (Fig. 2). High mutagenicity was found for TSP collected on those days. Backward trajectories of air masses on those days indicated that the air masses had traveled from mainland East Asia (Fig. 5). High correlation coefficients were found between the concentration of TSP and those of the chemical constituents and mutagenic activity without and with S9 mix (Table 3). JMA registered Asian dust events on March 8, 9, and 19 [2], and average dust extension coefficients higher than $0.066 / \mathrm{km}$, which indicates the occurrence of an Asian dust event [4], were found by LIDAR at Matsue on March 7, 8, 9, and 19 [3]. These results suggest that anthropogenic pollutants including mutagens were transported with Asian dust from mainland East Asia to Yurihama in March.

Several kinds of PAHs ratios were used to estimate the source of PAHs, and the $[\mathrm{FR}] /([\mathrm{FR}]+[\mathrm{PY}])$ ratio was most commonly used for PAHs in airborne particles [24-26]. To speculate the source of PAHs, we calculated the [FR]/ $([\mathrm{FR}]+[\mathrm{PY}])$ ratios in TSP collected at Yurihama in this study. Several studies investigated the $[\mathrm{FR}] /([\mathrm{FR}]+[\mathrm{PY}])$ ratios for many kinds of emitted particles and revealed that the ratios were greater than 0.5 for most coal and wood combustion samples, but smaller than 0.5 for petroleum combustion [24]. Liu et al. [25] measured atmospheric $[\mathrm{FR}] /([\mathrm{FR}]+[\mathrm{PY}])$ ratios at 46 sites in northern China in winter and reported that the ratios for most samples were greater than 0.5 , indicating a predominant influence of coal/biofuel combustion. Similarly, Wang et al. [26] examined $[\mathrm{FR}] /([\mathrm{FR}]+[\mathrm{PY}])$ ratios in Shanghai in autumn, winter, and spring. They revealed that the ratio in autumn was smaller than 0.5 and those in winter and spring were greater than 0.5 ; they concluded that wood and biomass burning was the largest source of PAHs contamination in the city. As shown in Fig. 4, the mean values of $[\mathrm{FR}] /([\mathrm{FR}]+[\mathrm{PY}])$ ratio for TSP collected at Yurihama in winter and spring were greater than 0.5 and both of them were significantly larger than that in summer. These results suggest that high levels of PAHs detected at Yurihama from January to March may be largely affected by coal and biomass combustion, like the atmosphere in northern and eastern China, and PAHs were transported from mainland East Asia.

\section{Conclusion}

Many TSP collected at Yurihama, a rural town in western Japan, from January to March showed high mutagenicity toward Salmonella typhimurium YG1024 without and with $\mathrm{S} 9$ mix. High levels of $\mathrm{Pb}$ and $\mathrm{SO}_{4}^{2-}$, which are indicators of transboundary air pollutions from mainland East Asia, were detected in the TSP. High levels of iron, which is an indicator of sand, was found in the highly mutagenic TSP collected in March, but not in TSP collected in January and February. High levels of PAHs were detected in the highly mutagenic TSP collected from January to March. The ratio of $[\mathrm{FR}] /([\mathrm{FR}]+[\mathrm{PY}])$ in the TSP collected in winter and spring suggested that main source of the PAHs was coal and biomass combustion, and that was reported to be major source of air pollutants in northern and eastern China. Backward trajectories of air masses on days when high levels of mutagenicity were found indicated that these air masses had traveled from northern or eastern China to Yurihama. These results suggest that high levels of mutagens were transported from mainland East Asia to western Japan, and this transportation accompanied Asian dust in March, but not in January and February.

\section{Availability of supporting data}

The data sets supporting the results of this article are included within the article.

\section{Abbreviations}

PAHs: Polycyclic aromatic hydrocarbons; TSP: Total suspended particles;

Pb: Lead; $\mathrm{SO}_{4}^{2-}$ : Sulfate ion; JMA: Japan Meteorological Agency; LIDAR: Light Detection and Ranging; IARC: International Agency for Research on Cancer; Fe: Iron; $\mathrm{NO}_{3}^{-}$: Nitrate ion; NIES: National Institute for Environmental Studies; BbF: Benzo[b]fluoranthene; BkF: Benzo[k]fluoranthene; BaP: Benzo[a]pyrene; IcdP: Indeno[1,2,3-cd]pyrene; $\mathrm{HNO}_{3}$ : Nitric acid; $\mathrm{HCl}$ : Hydrochloric acid; 
HF: Hydrofluoric acid; $\mathrm{HClO}_{4}$ : Perchloric acid; FR: Fluoranthene; PY: Pyrene; BaA: Benz[a]anthracene; DahA: Dibenz[a,h]anthracene; CHR: Chrysene; BghiP: Benzo[ghi]perylene; Ex: Excitation; Em: Emission; NOAA: National Oceanic and Atmospheric Administration.

\section{Competing interests}

The authors declare that they have no competing interests.

\section{Authors' contributions}

SC performed the experiment, the data analysis, the statistical analysis, and the writing the manuscript. HM, MA, KF and DA performed the experiment and the data analysis. TH and TO performed the experiment and coordinated the study. MW and KW participated in designing the study. NH performed the data analysis and the statistical analysis. TW conceived of the study, participated in designing the study and the analysis of data, and wrote the manuscript. All authors read and approved the final manuscript.

\section{Acknowledgements}

The authors thank Dr. Atsushi Shimizu at NIES for providing us with LIDAR data. This study was supported by the Environment Research and Technology Development Fund (C-1154) of the Japanese Ministry of the Environment and Health and Labour Sciences Research Grants for Research on Global Health Issues from the Ministry of Health, Labour, and Welfare of Japan. SC was granted scholarship assistance by Otsuka Toshimi Scholarship Foundation.

\section{Author details}

${ }^{1}$ Department of Public Health, Kyoto Pharmaceutical University, 1 Misasagi-Shichonocho, Yamashinaku, Kyoto 607-8412, Japan. ${ }^{2}$ Tottori Prefectural Institute of Public Health and Environmental Science, 526-1 Minamidani, Yurihamacho, Tottori 682-0704, Japan. ${ }^{3}$ Osaka City Institute of Public Health and Environmental Sciences, 8-34 Tojocho, Tennojiku, Osaka 543-0026, Japan. ${ }^{4}$ Department of Respiratory Medicine and Rheumatology, Tottori University Faculty of Medicine, 36-1 Nishimachi, Yonago 683-8504 Tottori, Japan. ${ }^{5}$ Department of Food and Nutrition, Faculty of Human Health, Sonoda Women's University, 7-29-1 Minamitsukaguchicho, Amagasaki 661-8520 Hyogo, Japan. ${ }^{6}$ Graduate Division of Nutritional and Environmental Sciences, University of Shizuoka, 52-1 Yada, Surugaku, Shizuoka 422-8526, Japan.

\section{Received: 29 August 2015 Accepted: 30 October 2015}

Published online: 08 December 2015

\section{References}

1. Uno I, Amano H, Emori S, Kinoshita K, Matsui I, Sugimoto N. Trans-pacific yellow sand transport observed in April 1998: a numeric simulation. J Geophys Res. 2001;106:18331-44.

2. Japan Meteorological Agency. "Data bank of global environment-Kosa.": http://www.data.jma.go.jp/gmd/env/kosahp/kosa_data_index.html (2015). Accessed in March 2015.

3. DSS - Dust and sand storms - MOEJ real-time DSS information (LIDAR DSS observation data page). http://soramame.taiki.go.jp/dss/kosa/en/index.html (2015). Accessed in March 2015.

4. Ueda K, Shimizu A, Nitta H, Inoue K. Long-range transported Asian dust and emergency ambulance dispatches. Inhalation Toxicol. 2012;24:858-67.

5. Zhao PS, Dong F, He D, Zhao XJ, Zhang XL, Zhang WZ, et al. Characteristics of concentrations and chemical compositions for $\mathrm{PM}_{25}$ in the region of Beijing, Tianjin, and Hebei, China. Atmos Chem Phys. 2013;13:4631-44.

6. International Agency for Research on Cancer (IARC): outdoor air pollution a leading environmental cause of deaths. http://www.iarc.fr/en/media-centre/ pr/2013/pdfs/pr221_E.pdf (2015). Accessed in March 2015.

7. Zhang $Y$, Tao S. Global atmospheric emission inventory of polycyclic aromatic hydrocarbons (PAHs) for 2004. Atmos Environ. 2009;43:812-9.

8. Watanabe T, Hasei T, Kokunai O, Coulibaly S, Nishimura S, Fukasawa M, et al. Air pollution with particulate matter and mutagens: relevance of Asian dust to mutagenicity of airborne particles in Japan. Genes Environ. 2014;36:120-36.

9. Hasei T, Sakaguchi M, Yoneda M, Wada M, Miyagawa S, Kobayashi K, et al. Development of an analytical method for strong mutagens/carcinogens, 3,9-dinitrofluoranthene and dinitropyrene isomers, in the environment and their particle-size distribution in airborne particles. Chromatographia. 2015;78:55-63.
10. Wedepohl KH. The composition of the continental crust. Geochim Cosmochim Acta. 1995:59:1217-32.

11. Mukai H, Tanaka A, Fujii T, Zeng Y, Hong Y, Tang J, et al. Regional characteristics of sulfur and lead isotope ratios in the atmosphere at several Chinese urban sites. Environ Sci Technol. 2001;35:1064-71.

12. Tsuji A, Hioki T. Detailed analysis of transboundary transport of Kosa and anthropogenic substances by size-segregated and highly time-resolved observation of ionic components and inorganic elements in ambient aerosols. J Jpn Soc Atmos Environ. 2013;48:82-91.

13. Lynch AJ, McQuaker NR, Brown DF. ICP/AES Analysis and the composition of airborne and soil materials in the vicinity of a lead/zinc smelter complex. J Air Pollut Control Assoc. 1980;30:257-60.

14. Funasaka K, Sakai M, Shinya M, Miyazaki T, Kamiura T, Kaneco S, et al. Size distributions and characteristics of atmospheric inorganic particles by regional comparative study in urban Osaka, Japan. Atmos Environ. 2003;37:4597-605.

15. Yonemochi S, Umezawa N, Matsumoto R. Evaluation of mass concentrations and chemical compositions of PM2.5 for five years in the north Saitama region. J Jpn Soc Atmos Environ. 2007;42:129-42.

16. Yahagi T, Nagao M, Seino Y, Matsushima T, Sugimura T. Mutagenicities of N-nitrosamines on Salmonella. Mutat Res. 1977;48:121-9.

17. Watanabe M, Ishidate M Jr, Nohmi T. Sensitive method for detection of mutagenic nitroarenes and aromatic amines: new derivatives of Salmonella typhimurium tester strains possessing elevated O-acetyltransferase levels. Mutat Res. 1990;234:337-48.

18. Coulibaly S, Minami H, Abe M, Hasei T, Sera N, Yamamoto S, et al. Seasonal fluctuations of air pollution in Dazaifu, Japan, and the effect of long-range transport from mainland East Asia. Biol Pharm Bull. 2015;38:1395-403.

19. Maron DM, Ames BN. Revised methods for the Salmonella mutagenicity test. Mutat Res. 1983;113:173-215.

20. Air Resources Laboratory. "HYSPLIT-Hybrid Single Particle Lagrangian Integrated Trajectory Model. http://www.ready.noaa.gov/HYSPLIT.php (2015). Accessed in March 2015.

21. Einistö P, Watanabe M, Ishidate M Jr, Nohmi T. Mutagenicity of 30 chemicals in Salmonella typhimurium strains possessing different nitroreductase or O-acetyltransferase activities. Mutat Res. 1991;259:95-102.

22. Wang Y, Yao L, Wang L, Liu Z, Ji D, Tang G, et al. Mechanism for the formation of the January 2013 heavy haze pollution episode over central and eastern China. Sci China Earth Sci. 2014;57:14-25.

23. Zhang YL, Huang RJ, Haddad IE, Ho KF, Cao JJ, Han Y, et al. Fossil vs. non-fossil sources of fine carbonaceous aerosols in four Chinese cities during the extreme winter haze episode of 2013. Atmos Chem Phys. 2015;15:1299-312.

24. Yunker MB, Macdonald RW, Vingarzan R, Mitchell RH, Goyette D, Sylvestre S. PAHs in the Fraser River Basin: a critical appraisal of PAH ratios as indicators of PAH source and composition. Org Geochem. 2002;33:489-515.

25. Liu S, Tao S, Liu W, Liu Y, Dou H, Zhao J, et al. Atmospheric polycyclic aromatic hydrocarbons in north China: a winter-time study. Environ Sci Technol. 2007;41:8256-61.

26. Wang XY, Li QB, Luo YM, Ding Q, Xi LM, Ma JM, et al. Characteristics and sources of atmospheric polycyclic aromatic hydrocarbons (PAHs) in Shanghai, China. Environ Monit Assess. 2010;165:295-305.

\section{Submit your next manuscript to BioMed Central and take full advantage of:}

- Convenient online submission

- Thorough peer review

- No space constraints or color figure charges

- Immediate publication on acceptance

- Inclusion in PubMed, CAS, Scopus and Google Scholar

- Research which is freely available for redistribution 